\title{
ANALYSIS AND DESIGN OF A BASE-ISOLATED REINFORCED CONCRETE FRAME BUILDING
}

\author{
L. M. Megget*
}

\section{$\underline{\text { ABSTRACT }}$}

The paper describes the dynamic and static analyses and design of a four storey ductile reinforced concrete frame structure isolated from the foundations by elastomeric bearings incorporating lead energy dampers. Results from inelastic, time-history analyses for the isolated and nonisolated structure are compared for several input earthquake motions. The benefits of energy dampers in reducing the isolated building's response (shears, plastic hinge demands and interstorey drifts) are detailed. Differences from conventional ductile design and detailing as well as design recommendations are included.

\section{INTRODUCTION}

The proposed building is a four storey reinforced concrete frame structure $(97 \mathrm{x}$ $40 \mathrm{~m}$ plan dimensions), including a basement, with column grid lines at $7.2 \mathrm{~m}$ centres. Fig. 1 shows an architectural perspective of the building, which will be located in Wellington. The structure is the first building known to be designed with baseisolation using elastomeric rubber bearings with lead energy dampers included to reduce the structure's seismic response. The bearings and dampers are situated in a crawl space below the basement beams and sit on the foundation pads.

The building contains large open plan offices with several full height partitioned offices which may be repositioned in the future. The interstorey heights are $5 \mathrm{~m}$ from basement to ground floor and $4 \mathrm{~m}$ above ground floor while the internal beams of the first, second and roof levels are haunched to allow space for the mechanical services. Deep precast concrete cladding panels are separated from the beams and slabs to allow the structure to act as a beam-hinging system. The plant rooms are situated on the second and roof levels and consist of steel portal frames. Also there are large steel canopies with $45^{\circ}$ sloping glazing covering the entrance foyers. Fig. 2 shows a typical transverse section through the structure.

\section{BUILDING ISOLATION}

\subsection{Bearings and Dampers}

The utilisation of natural rubber bearings as isolators to protect the building above from large earthquake forces has been covered in the literature $(1,2,3)$ mainly on a theoretical basis. The work of the DSIR, Physics and Engineering Laboratory in the development and theoretical performance of hysteretic dampers for use in bridges and structures has been published $(4,5,6,9)$. Also intense fire tests on bearings have shown little degradation of stiffness (8). The original scheme was to isolate the

* Senior Lecturer, School of Architecture, Victoria University of Wellington. building on elastomeric bearings and use 80 mild steel flexural cantilever energy absorbers (one per column) as dampers, fixing them between the foundation footings and the basement slab above. During final design the DSIR developed and tested an elastomeric bearing including a lead plug as the energy damper (9). The cylindrical lead plug deforms in shear between the internal steel plates within the rubber bearing, while the bearing carries the column axial load. Skinner and McVerry suggest that the elastomeric bearing's shear stiffness should be approximately equal to the average axial dead plus seismic live load per metre of shear deformation. Also the yield capacity of a lead damper should be about $5 \%$ of the average axial load per bearing. The rubber and lead plug energy damper's hysteretic properties have been calculated using these relationships - namely the rubber bearing shear stiffness $=\frac{122000}{80}=1525 \mathrm{kN} / \mathrm{m}$ and the lead damper shear 80 force at yield, $F(a)=\frac{122000 \times 0.05}{80}=76 \mathrm{kN}$.

Fig. 3 shows the assumed shear force shear deformation hysteresis curve of the rubber/lead damper used in the analysis (see section 3.1). The plastic stiffness of rubber and lead is greater than the rubber alone due to the lead not being elastic - perfectly plastic.

The principal properties of the rubber/ lead damper are a stiffness of $10000 \mathrm{kN} / \mathrm{m}$ up to yield and a plastic stiffness of $2500 \mathrm{kN} / \mathrm{m}$. The stiffnesses of the hysteresis curve can be adapted as desired by choice of bearing and lead plug diameter. On the highest loaded column the dead plus full live load is $3000 \mathrm{kN}$ and the dead plus seismic live load is $2200 \mathrm{kN}$. The mean column dead plus seismic live load is about $1500 \mathrm{kN}$.

The moulded elastomeric bearing that best fits this specification is a $650 \mathrm{~mm}$ diameter by $197 \mathrm{~mm}$ thick bearing with 9-5 $\mathrm{mm}$ thick steel internal plates with $15 \mathrm{~mm}$ thick rubber layers and $10 \mathrm{~mm}$ thick rubber side cover (SAA part number 17:15:09C, ref. 11). An estimated $120 \mathrm{~mm}$ diameter lead plug passes through the centre of the bearing. 
See Fig. 4 for a drawing of the damper/bearing and its fixings to the structure. The code of Practice(11) states a mean shear stiffness is $1740 \mathrm{kN} / \mathrm{m} \pm$ a tolerance of $20 \%$ for the rubber bearing alone. The maximum shear strain allowed in bridge bearings is normally $50 \%$ (19). However it was decided that for a structure a maximum shear deformation of $100 \%$ is permissible, as such large deformations will only occur a few times during the structure's life - as long as the bearing does not become unstable under the seismic axial load. The preliminary dynamic computer analysis used a model with a single column with one mass per floor and modelled all the dampers as a simple bi-linear spring.

Maximum rubber bearing shear deformations of about 100 and $150 \mathrm{~mm}$ under $1.5 \mathrm{El}$ Centro and artificial Al earthquakes were evident, respectively.

Thus a maximum shear deformation of $150 \mathrm{~mm}$ in the bearings was used throughout the design. This necessitated a $150 \mathrm{~mm}$ gap between the basement $\mathrm{slab}$ and the retaining walls around the building's periphery. As this gap occurs in the basement carpark/ storage area there are few architectural problems - the gap will be covered by a sliding grill. At ground floor level the entrance steps go over the gap and the ramp incorporates a drain under the gap with a sliding grill over the drain, see Fig. 5 for details. Special service connections are required between the exterior and interior of the building to allow the movements of $\pm 150 \mathrm{~mm}$ in any horizontal direction. At the time of writing, details of the special connections were not available.

\subsection{Design Earthquake}

The 1940 El Centro earthquake (NorthSouth component) has been used as the basic earthquake for design codes and dynamic analyses for years. The proposed building will stand near a class I fault on alluvial soils which extend at least $100 \mathrm{~m}$ below. After consideration of site conditions and because of the experimental nature of the building it was decided to use $1.5 \mathrm{El}$ Centro (10 seconds) as the design earthquake at basement level (i.e. peak ground acceleration is $0.523 \mathrm{~g})$. The maximum creditable earthquake used was the artificial Al motion (12) which is equivalent to a magnitude 8 or greater earthquake in the vicinity of the fault. Major shaking occurs for about 40 seconds and this length of record was used in the design.

\section{STRUCTURAL ANALYSES}

\subsection{Dynamic}

Inelastic, bi-linear, dyanamic timehistory analyses were completed using the University of California, Berkeley's computer program DRAIN-2D(13) on the MWD's IBM $370 / 168$ computer. A typical 2-dimensional transverse frame was modelled, as shown in Fig. 6, with the bearing/dampers modelled as horizontal truss members with a bi-linear hysteresis curve as in Fig. 3. This hysteresis parallelogram closely approximates the small scale bearing/damper force - shear deformation relationship tested experimentally by the DSIR(9). Two full scale bearing/dampers will be tested prior to construction. The program uses the direct stiffness method with the nodal displacements relative to ground as unknowns. The dynamic response is determined by a step-by-step procedure based on the assumption of a constant acceleration within any step.

Fig. 6 also shows the member sizes and reinforcement assumed. The slab is a precast system spanning transversely. The cracked-section moments of inertia used were 0.7 I gross and I gross for the beams and columns respectively. The gross crosssectional areas were used throughout while two-thirds of the area was assumed as the shear area for shear deformations. The contributing slab width used was $1.8 \mathrm{~m}$ by $200 \mathrm{~mm}$ thick although no slab reinforcement was included in the yield moment calculation of the beams.

These beam yield moments were calculated using the areas of steel as in Fig. 6 and assuming a yield stress of $1.15 \mathrm{fy}$, allowing for average overstrength above the specified minimum of $275 \mathrm{MPa}$ and a capacity reduction factor, $\varnothing=1.0$. A reinforcing yield stress of $275 \mathrm{MPa}$ was used to calculate the yield moment - axial load interaction diagram of the columns. The interaction curve was approximated to three straight Iines, one from maximum tension - no moment to no axial load point, the second from no axial load to balance point and third line from balance to maximum compressive axial load, see (13). The assumed plastic stiffness of the beams and columns after yielding was taken as $2 \%$ of the elastic stiffness up to yield and no degrading stiffness with increasing cyclic plasticity was included. The program accounts for inelastic effects by allowing the formation of concentrated point hinges at the end of elements when the yield moment specified is exceeded.

Rigid end-distances of length $0.25 \mathrm{~m}$ were used at both beam and column ends. Plastic hinges form at the end of these rigid zones. The dead and seismic live loads on the beams and columns were added to the structure as fixed end moments and lumped masses prior to the earthquake input. The lateral inertia masses were lumped at each floor level. The integration time step used was 0.010 and 0.025 seconds for the El Centro and $A 1$ earthquake records respectively. A linear combination of initial stiffness - proportional and massproportional viscous damping has been assumed for the structure. The damping distribution among the initial component modes was defined in terms of the percentage of the critical damping for the system's first and second modes. 3\% of critical damping was used for the isolated structure as suggested by Skinner(10). The principal modes of the structure on its bearings are the period of vibration of the structure as a rigid mass vibrating on the bearings/dampers $(T=2.0$ seconds) and the natural period of the frame structure alone ( $T=3.0$ second). The actual fundamental period of the isolated structure varies between about 0.8 and 2.0 seconds, depending on the amplitude of the lateral vibration. During a major earthquake the dampers will be yielding for a majority of the time of intense ground shaking and hence a period based on the post yield stiffness of bearings and dampers $(2.0$ seconds) was used. The 
structure's first and second mode periods ( $\mathrm{T} 1=0.3$ and $\mathrm{T} 2 \simeq 0.08$ seconds) were used with corresponding 3 and $5 \%$ of critical damping values for the comparative analysis of the non-base isolated structure. These damping values may be lower than those assumed for reinforced concrete frames under major earthquakes. However until severe cracking and hinging occurs 38 of critical damping for the first mode is reasonable for a pure frame with no lateral load resisting walls or cladding panels and very few internal partitions.

\subsection{Maximum Column Shears}

Fig. 7 shows the sum of the column shear forces up the building for the isolated and non-isolated structures under 10 seconds of 1.5 El Centro and the isolated model under 40 seconds of Al earthquake. The N.Z. Loading Code(14) static shear force distribution for a base shear coefficient, $\mathrm{Cd}=0.19$ is also included. The non-isolated structure's shear force distribution shows only maximum values; the greater of the positive or negative shear at any level being drawn on the positive side.

The maximum base shear of the isolated building under $1.5 \mathrm{El}$ Centro and with $3 \%$ critical damping was $19.7 \%$ of the model building frame's dead plus seismic weight, Wt; almost equal to Skinner's(10) single mass linear resonator with base isolation under the same earthquake input and with 3 of damping. The same structure but with $5 \%$ of critical damping resulted in a maximum base shear of $0.18 \mathrm{Wt}$. The reduction in maximum column shears up the building was about 10 for the increased damping.

The response under $A l$ earthquake is greater than the $1.5 \mathrm{El}$ Centro response with a maximum base shear at bearing level of $0.26 \mathrm{Wt}$. This is due to Al having a spectrum intensity $50 \%$ greater than El Centro even though the peak acceleration of $1.5 \mathrm{EI}$ Centro is greater than Al's peak acceleration, $0.35 \mathrm{~g}$. The maximum base shear force for the non-isolated structure at basement was twice $(0.38 \mathrm{Wt})$ that of the isolated structure at foundation level for $1.5 \mathrm{El}$ Centro earthquake. Note that the dynamic shear envelopes for the isolated structure suggest a near uniform distribution of lateral force up the structure rather than the usual static inverted triangular distribution of non base-isolated buildings.

\subsection{Bearing and Lead Damper}

Fig. 8 shows the shear deflection timehistory (relative to ground) of a bearing and damper during 10 seconds of 1.5 El Centro together with the lateral deflection at roof level. The El Centro ground displacement (from double integration of the acceleration record) is also plotted as a comparison. The lead plug is "yielding" within the rubber bearing for about $80 \%$ of the first 10 seconds of record analysed. The period of response of the bearings and thus the predominent period of shaking of the building above ranged between 1 and 2 seconds when the dampers are yielding. This agrees with Skinner's results for input earthquake accelerations between one and two $\mathrm{x}$ El Centro. The maximum damper shear deformation was $105 \mathrm{~mm}$ at 6.15 seconds while the permanent set of the lead damper after 10 seconds of response was nearly $6 \mathrm{~mm}$.

Fig. 9 shows 25 seconds of response of a damper/bearing shear deformation under Al earthquake. The predominent period of excitation is nearer 2.0 seconds for the larger plastic cycles. The maximum shear deflection was $151 \mathrm{~mm}$; the limit of free movement before the basement slab runs into the retaining walls. There were 13 peaks (for 40 seconds of record) at shear deformations of $\pm 100 \mathrm{~mm}$ or greater.

\subsection{Hinge Formation and Rotational Ductilities}

Under $1.5 \mathrm{El}$ Centro only the roof beam yielded (rotational ductilities less than two) and there was no hinge reversal. Note that the applied vertical loads at roof level are higher than the other floors due to the weight of the plant rooms and there is very little dead load on the other beams due to the slabs spanning in the transverse direction. No column hinges formed at any time. By comparison the non-isolated structure under the same earthquake had all the beams yielding for ground floor and above, most showing several cycles of hinge reversal. Also all the columns formed hinges for short periods of time, often at both top and bottom and with hinge reversal. The maximum rotational ductilities for the worst roof beam hinge were +9 and -5 , while the accumulated rotational ductilities over the 10 seconds of response were +37 and -22 .

Fig. 10 shows the maximum beam moments recorded during $1.5 \mathrm{El}$ Centro for the isolated structure compared with the yield moment calculated as described in section 3.1. Note that the basement and ground floor beams reach only about $50 \%$ of the yield capacity available while the second floor beams nearly yield. This was due mainly to the triangular seismic load distribution used for the member design, see section 4, whereas the dynamic lateral forces follow a distribution up the structure in the isolated response which closely follows the lateral mass distribution. In other words the dynamic overturning moment is less for the isolated structure than the equivalent code static lateral distribution with a similar base shear coefficient.

\subsection{Interstorey Drifts}

Fig. Il shows the maximum interstorey drifts up the building from the dynamic analyses for both isolated and non-isolated structures. Under both $1.5 \mathrm{El}$ Centro and Al earthquakes the maximum interstorey drifts for the isolated structure were about $10 \mathrm{~mm}(\Delta / \mathrm{h} \simeq 0.002)$ and were uniform over the structure's height. However in the case of the non-isolated structure, the interstorey drifts increase dramatically up the building reaching a maximum of $52 \mathrm{~mm}$ between the second and roof levels. This was due to the higher roof mass and lower stiffness - two columns instead of the 4 for the lower floors - and probable higher mode effects. A deflection ductility factor of 7.6 was recorded at roof level (maximum roof deflection divided by roof deflection when first hinge forms). This compares well with Skinner's (10) non-isolated structure assuming hinging first occurs at a base shear of about 0.34 Wt. A ductility demand of 1.6 was required for the isolated frame 
above the energy dampers, again showing good agreement.

\subsection{Roof Accelerations}

The maximum roof accelerations recorded in the dynamic analyses for $1.5 \mathrm{El}$ Centro and $\mathrm{Al}$ were $0.70 \mathrm{~g}$ and $0.64 \mathrm{~g}$ respectively. The non-isolated structures response showed accelerations of $1.02 \mathrm{~g}$ and $0.96 \mathrm{~g}$ under $1.5 \mathrm{El}$ Centro and $\mathrm{Al}$ respectively approximately $50 \%$ greater than the baseisolated structure.

\section{DESIGN LOADINGS AND ELASTIC ANALYSIS}

\subsection{Design Loadings}

The transverse spanning direction of the ribbed flooring was used to reduce the imposed loads and gross gravity and earthquake moments on the outer transverse frames. A full live load of $4 \mathrm{kPa}$ was used for all floors and the roof. However $3 \mathrm{kPa}$ was used for the beam design and also for the static seismic lateral force calculations, $\mathrm{Ls}=\mathrm{L} / 3=1 \mathrm{kPa}$. A live load of $5 \mathrm{kPa}$ was used for the plant room floors. As the basement is isolated from the foundations by the bearings, the basement floor loads were included in the seismic weight. The design earthquake, $1.5 \mathrm{El}$ Centro, produced a maximum dynamic base shear equivalent to nearly $0.20 \mathrm{Wt}$ and this was used as the design static base shear force, $(\mathrm{Cd}=0.20)$. This is equivalent to the non-isolated base shear coefficient (NZS 4203, (14)) with an additional $20 \%$ for torsion included. Had the structure been designed as non-isolated a torsional increase of up to $54 \%$ over the basic base shear would have been required for the exterior transverse frames.

Torsional vibration is expected to be considerably reduced for base-isolated structures, see reference 10.

\subsection{Elastic Analysis}

ICES-STRUDL ${ }^{(15)}$ analyses were completed on typical transverse and longitudinal frames using 0.5 and 0.7 of the gross moment of inertia for beams and columns respectively. The approximate triangular distribution of lateral seismic force up the structure (14) was used with zero level taken at the bottom of the elastomeric bearings. This represents a conservative design load when compared with the dynamic analyses which had confirmed a uniform distribution of lateral load as in (10) for the particular earthquake records used in the analyses. The designers felt that the inverted triangular distribution should be used for this initial base isolated prototype. Fig. 10 also shows the elastic analysis beam moments as a comparison with the dynamic, inelastic analysis moments.

\section{FRAME DESIGN}

\subsection{Beams and Columns}

A maximum redistribution of $20 \%$ on the $' D+1.3 L+E$ ' negative moment was used for the beam design, ACI 318-71(16). The maximum main reinforcement ratios were restricted to $1.5 \%$ and $3 \%$ in beams and columns respectively. Cranks in beam steel at laps were eliminated by using two bar layers top and bottom, each layer comprising 3 bars and half the bars cut-off at one point. Thus over a mid-span zone only half of the total area of reinforcement, top and bottom, is effective. The interior first, second and roof beams have been haunched and 3 extra RI2 site welded U bars detailed at the mid-span end of the haunch to restrain the cranked lower beam bars from straightening. The haunch details were similar to those in the full-size beam column joint tested by MWD Central Laboratories (17).

The capacity design approach has been used in the column flexure and beam and column shear design but only uniaxial beam yielding was assumed. The columns have not been designed for bi-axial actions, see section 5.2 for the reason. The columns were capacity designed using high strength reinforcing ( $380 \mathrm{MPa}$ ) before the recommendation of the Discussion Group on Seismic Design of Ductile Moment Resisting Reinforced Concrete Frames(21) were published. During the design check phase consideration has been given to amending the main column reinforcement to mild steel (275 MPa). This seems reasonable due to the absence of beam hinging in the dynamic analyses. The minimum centreline spacing of $100 \mathrm{~mm}$ for the main column bars was detailed to facilitate the use of mechanical splices. This allowed a maximum of 24-D32 bars in the $800 \mathrm{~mm}$ square column.

\subsection{Joint Shear}

The horizontal beam/column joint shear was calculated from the tension reinforcement area on each side of the joint multiplied by the overstrength yield stress of the steel minus the column shear above the joint estimated from the elastic analysis. The overstrength and strain-hardening factor was taken as 1.25 on the nominal yielding only. From the dynamic analyses it was evident that the probability of beams yielding in both directions at the same instant is extremely small in the baseisolated building, even during earthquakes of the level of Al. The number of joint tie-sets required was calculated using 5 tie-legs effective out of the 6 legs available per tie-set (4 long and 2 short), a capacity reduction factor, $\phi=0.85$ and no shear contribution taken by the joint concrete. Also the $2 / 3$ factor for the ineffectiveness of shear ties has not been included. Critical joints require 5 ties/set of R20 ties but this allowed little open area for concrete placement and thus 3-R24 ties/set were detailed. The slab reinforcement was not included in the beam over strength capacity calculations and thus a proportion of the joint shear will need to be carried by a diagonal concrete compressive strut if beam hinging actually occurs. Note that even with the low beam steel ratios the available space for joint ties is at a premium and had the joints been designed for bi-axial shear, the required number of ties would not have fitted within the depth of beam available. All beams would have to be at least $200 \mathrm{~mm}$ deeper, adding one metre to the building's height.

\section{DESIGN RECOMMENDATIONS AND CONCLUSIONS}

\subsection{Bearing Stiffness}

This is the first building designed 
with base-isolation and using energy dampers to absorb the seismic energy. Thus no isolated structure has experienced an earthquake and no actual response is available. For this reason the frame was designed as a ductile frame with a high static base shear coefficient equivalent to the maximum dynamic base shear recorded by the isolated structural model during $1.5 \mathrm{El}$ Centro earthquake. The bearing and dampers have to be stiff enough before the lead dampers yield to resist the worst wind forces. The sum of the yield forces of all the bearings and dampers was equal to nearly $7 \%$ of the structure's dead plus seismic live weight. Normally the elastomeric bearings alone will have a stiffness approximately equal to 208 of the damper stiffness prior to yielding of the damper. After yielding the overall stiffness of the bearing and damper will be slightly greater than the rubber bearing stiffness alone, see (9). The bearings and dampers should be detailed so they can be removed after a major earthquake. They should also be easily accessible for inspection at any time. Bearings have been tested through hundreds of cycles at shear strains greater than $50 \%$ with little change in their force-displacement characteristics (18) but long term effects are not fully known.

\subsection{Bearings Displacements}

The proposed building's columns did not exhibit any tensile axial force during the dynamic analyses but care is needed in detailing the connections between bearings and structure so that the bearing will not jump out of position if tension does occur in a major shake while the building is moving laterally. Several analyses were completed with the vertical component of the input earthquake included as well as the horizontal component. The resulting responses showed insignificant differences from the analyses with a horizontal earthquake component only and again no column experienced tensile axial forces (even for a fraction of a second). The maximum allowable shear strains of the bearings can be $100 \%$ since this strain should only occur for a few cycles during the maximum creditable earthquake likely to be experienced. Also the elapsed time at this level of strain will be very small - of the order of 0.1 second.

The structure's allowable movement on the bearings should be limited so that shear strains greater than $100 \%$ are not possible. The computer model used was unable to examine the response of the building hitting the retaining walls, but from impact until the bearings and dampers begin to act again on reversal, the structure will tend to act as a convential non-base isolated building. If the structure hits the retaining wall at accelerations greater than about $0.5 \mathrm{~g}$ shear failure of the wall is likely and also greater beam hinging will occur.

\subsection{Distribution of Inertial Forces}

The lateral inertial forces up the structure showed more of a uniform distribution with mass than the code's static, approximately inverted triangular distribution actually used to find the design moments. No higher mode effects were evident from the analyses and hence the structure approximately responds as a very stiff object vibrating on its isolators, which respond at a period of between 1 and 2 seconds. Low rise structures could therefore be designed for an equivalent static uniform lateral force distribution up the structure. Priestley et al (20) reported that an interaction time of 0.005 seconds was required to eliminate moment-overshoot and clearly produced higher mode effects for base isolated shear wall analyses. A check analysis was performed for the base isolated structure under Al earthquake with an iteration time of 0.005 seconds. There were negligible changes to the response and no higher mode effects were visible for the base-isolated frame.

\subsection{Ductility Demand}

The level of hinging in the base-isolated structure during major earthquakes was negligible and thus lower levels of ductile design and detailing should be possible. Bi-axial beam yielding effects on column shear and joint shear design need not be considered for uniform buildings due to the reduced response of the isolated structure above the bearings. Also detailing to uni-axial yielding levels should be sufficient for joint shear as the probability of beams hinging in both direction at once at any joint is very small.

\subsection{Interstorey Drifts}

The interstorey drifts for the nonisolated structure are about twice, on average, those for the base-isolated building and the accelerations are approximately halved for the isolated case. The second floor to roof interstorey drift was five times the isolated structure's drift. Thus the expensive secondary damage in medium and major earthquakes will be minimised and separations of partitions and glazing should not be necessary in base-isolated structures. This will be a major cost saving. The seismic force factor for parts and portions, Kp(14) of base-isolated low rise structures could be halved. This particularly applies to precast concrete cladding panels and mechanical services. This reduction is due to the reduced accelerations evident from the response of the isolated structure.

\subsection{Base-Isolation Cost and Savings}

The estimated cost of the bearing/ dampers, fixings, their installation and extra foundation excavation and foundation beams has been estimated at $3.5 \%$ of the total building cost. This increased cost can be equated with the cost required for the non-isolated building to provide a full bi-axial ductile design, viz. deeper beams, larger columns, more reinforcement and greater seismic separations. The additional cost of extra architectural details partition separation, deeper panels and glazing is also significant. Cost studies for these latter items are not available at time of writing.

In future isolated structures it should be possible to position the bearings and dampers in the columns between basement and ground floor levels, as in Fig. 12, thus eliminating the need for separate foundation beams and clear space below basement beam 
level.

\section{ACKNOWLEDGEMENTS}

The permission of the Commissioner of Works, N. C. Mcleod, to publish this paper is acknowledged.

Grateful acknowledgement is made of the advice and guidance received from o. A. Glogau, Chief Structural Engineer, and T. N. Mitchell, District Structural Engineer, MWD.

The author also acknowledges the advice given by R. I. Skinner, R. G. Tyler and $W$. H. Robinson of the Physics and Engineering Laboratory, Department of Scientific and Industrial Research.

\section{REFERENCES}

1. Derham, C. J. and Learoyd, S. B. B. "The Use of Natural Rubber Foundation Springs for Earthquake Portection", 4 th Southeast Asian Conference on Soil Engineering, Kuala Lumpur, Malaysia, April 1975.

2. Derham, C. J., Wotton, L. R. and Learoyd, S. B. B., "Vibration Isolation and Earthquake Protection of Buildings by Natural Rubber Mountings", N. R. Technology, Vol. 6, Part 2 1975, pp $21-33$.

3. Lindley, P. B., "Engineering Design with Natural Rubber", N R Technical Bulletin, 3rd Ed, Natural Producers Research Association, London, 1970.

4. Skinner, R. I., Kelly, J. M., and Heine, A. J., "Energy Absorption Devices for Earthquake Resistant Structures", Proceedings 5th World Conference in Earthquake Engineering, Paper 370, Session 8C, Rome, Italy, May 1973.

5. Kelly, J. M., Skinner, R. I. and Heine, A. J., "Mechanisms of Energy Absorption in Special Devices for Use in Earthquake Resistant Structures", Bull. N.Z. Society of Earthquake Engineering, Vol. 5, No. 3, Sept. 1972, pp 63-88.

6. Skinner, R. I., Beck, J. L. and Bycroft, G. N., "A Practical System for Isolating Structures from Earthquake Attack", Int. Journal Earthquake Engineering Structural Dynamics, Vol. 3, No. 3, 1975 .

7. Robinson, W. H. and Greenbank, L. R., "An Extrusion Energy Absorber Suitable for the Protection of Structures During an Earthquake", Earthquake Engineering and Structural Dynamics. Vol. 4, pp 215-259, 1976.

8. Derham, C. F., "Fire Resistance of Steel-Laminated Natural Rubber Bearings" NR Technology, Vol. 7, Part 2, 1976.

9. Robinson, W. H. and Tucker, A. G., "A Lead-Rubber Shear Damper", Bull. N.Z. Nat. Soc. for Earthquake Engineering, Vol. 10, No. 3, September, 1977, pp 151-153.

10. Skinner, R. I. and McVerry, G. H., "Base Isolators for Increased Earthquake Resistance of Buildings", Bull. N.Z. Nat. Soc. for Earthquake Engineering, Vol. 8, No. 2, 1975, pp. 93-101.

11. Standards Association of Australia AS1523-1976, "Elastomeric Bearings for Use in Structures".

12. Jennings, P. C., Housner, G. W. and
Tsai, N. C., "Simulated Earthquake Motion", Earthquake Engineering Laboratory, California Institute of Technology, 1968.

13. Kanaan, A. E. and Powell, G. H., "DRAIN-2D, A General Purpose Computer Program for Dynamic Analysis of Inelastic Plane Structures", Earthquake Engineering Research Centre, University of California, Berkeley, September 1973.

14. N.Z. Standard, NZS 4203:1976, "Code of Practice for General Structural Design and Design Loadings for Buildings".

15. Logcher, R. D. et al, "ACES STRUDL-II The Structural Design Language Engineering". Massachusetts Institute of Technology, Cambridge, Mass, November 1968.

16. American Concrete Institute, "Building Code Requirements for Reinforced Concrete (ACI 318-71)", Detroit, Michigan.

17. Edmonds, F. D. and Wood, J. H., "Testing of Two Reinforced Concrete Beam Column Assemblies Under Simulated Seismic Loading - Second Series", MWD Central Laboratories Report $5-77 / 5$ to be published.

18. Tyler, R. G., "Dynamic Tests on Laminated Rubber Bearings", Bull. N.z. National Society for Earthquake Engineering, Vol. 10, No. 3, Sept. 1977, pp 143-150.

19. Ministry of Transport, London "Provisional Rules for the Use of Rubber Bearings in Highway Bridges", 1962.

20. Priestley, M. J. N., Crosbie, R. I. and Carr, A. J., "Seismic Forces in BaseIsolated Masonry Structures", Bull. N.Z. National Society for Earthquake Engineering, Vol. 10, No. 2, June 1977, pp 55-68:

21. Paulay, T., "Section G: Columns Evaluation of Actions", Bulletin of the N.Z. National Society for Earthquake Engineering, Vol. 10, No. 2, June 1977, pp 85-94.

Paper received 17 October, 1978. 


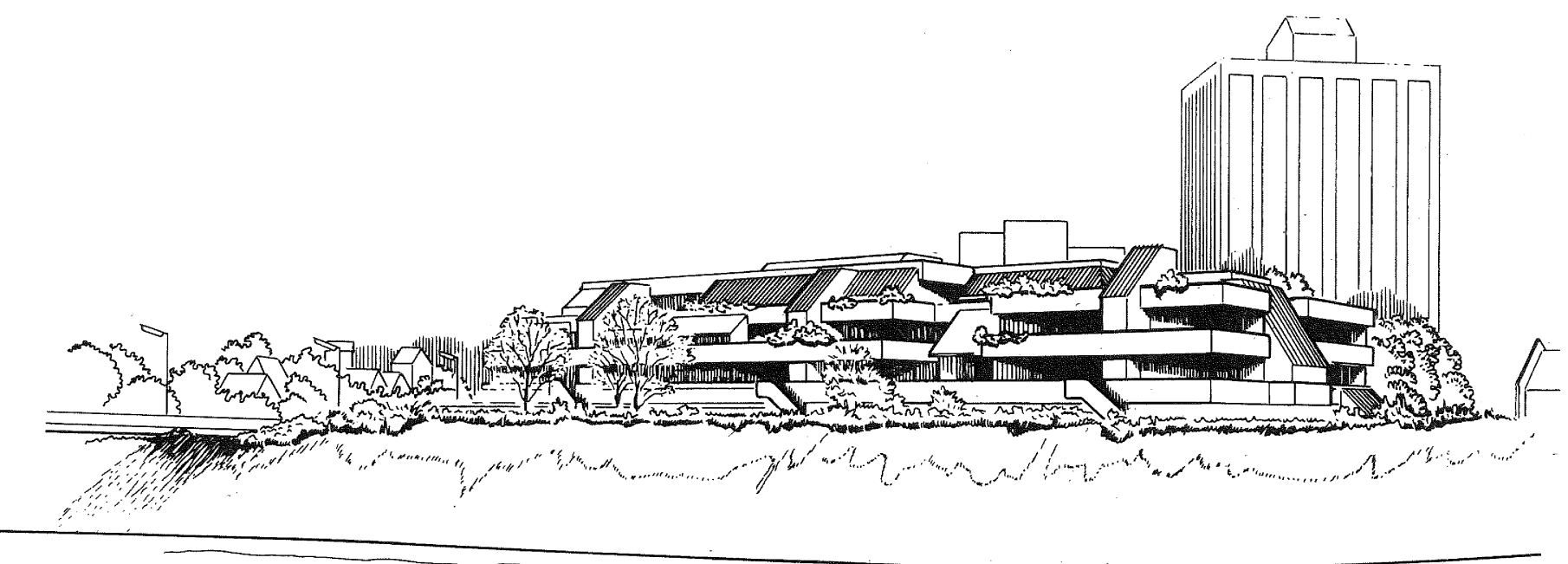

FIGURE 1: ARCHITECTURAL PERSPECTIVE OF THE PROPOSED BUILDING

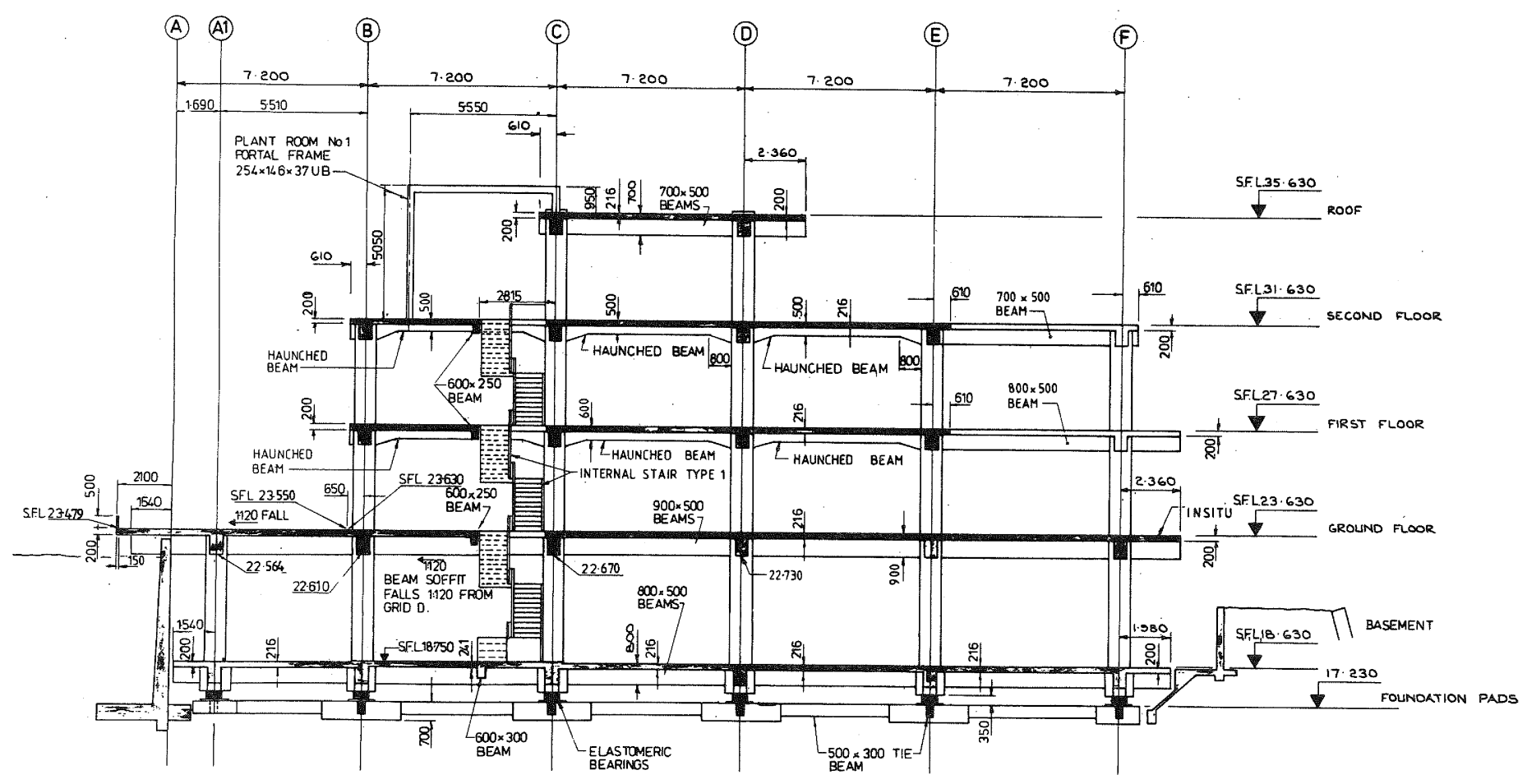

FIGURE 2: TRANSVERSE SECTION THROUGH THE BUILDING 


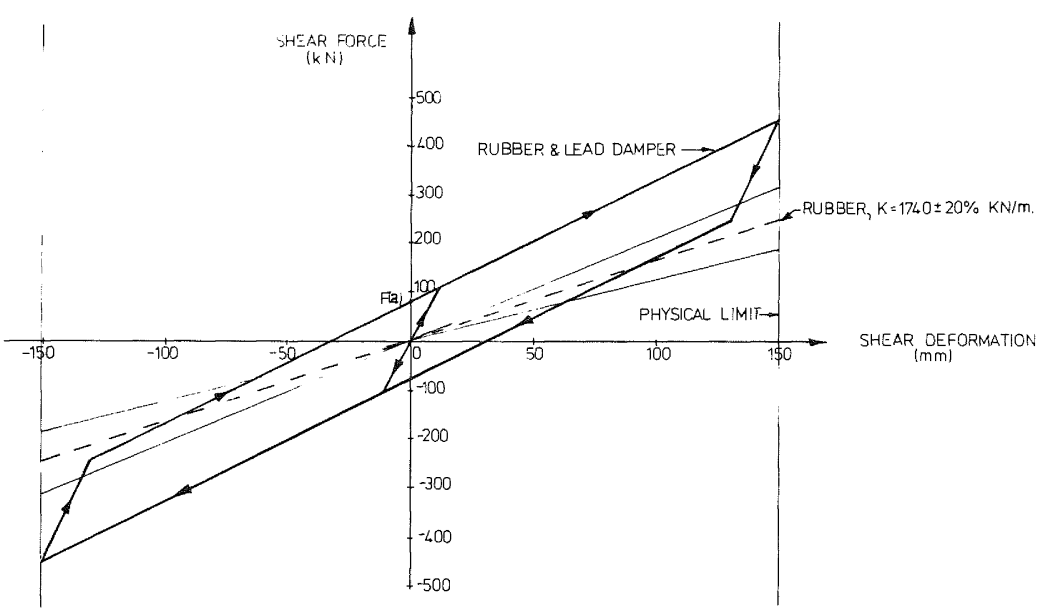

FIGURE 3: IDEALISED BEARING/DAMPER HYSTERESIS CURVE
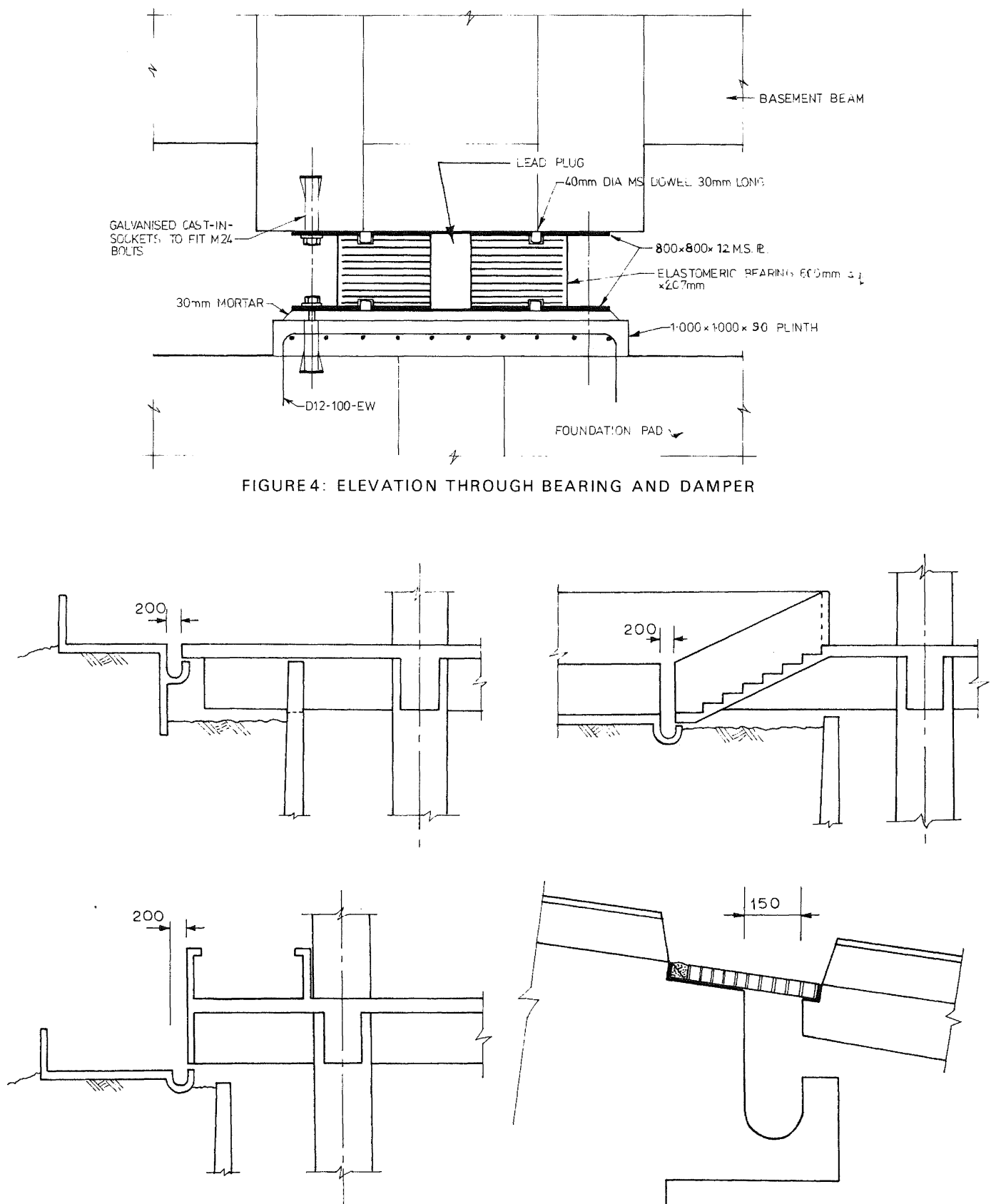

FIGURE $5 a$ \& $b$ : TREATMENT OF ISOLATION GAP BETWEEN BUILDING AND SURROUNDING ENTRANCE WAYS AT GROUND LEVEL 

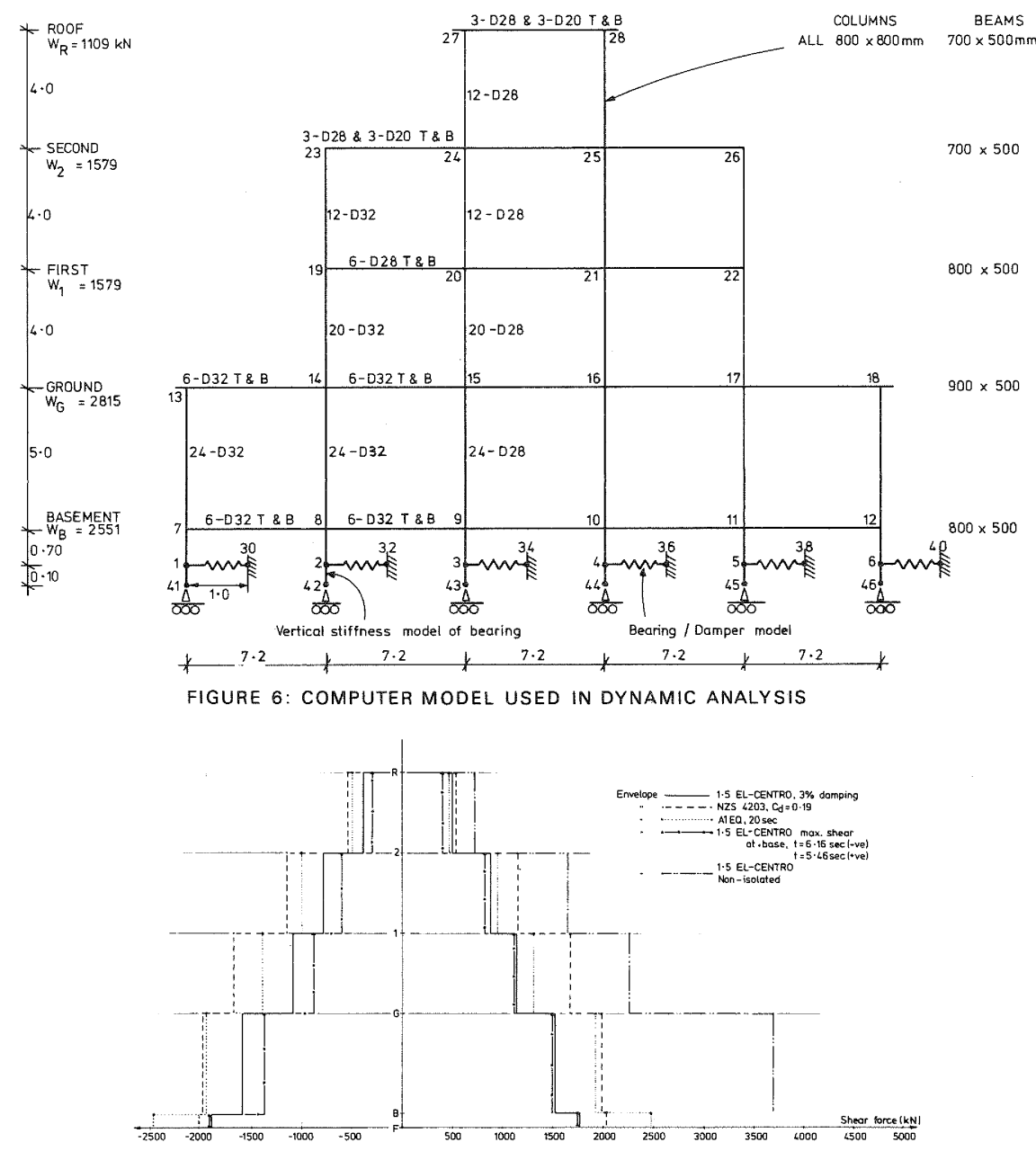

FIGURE 7: MAXIMUM SHEARS UP THE BUILDING UNDER VARIOUS EARTHQUAKES

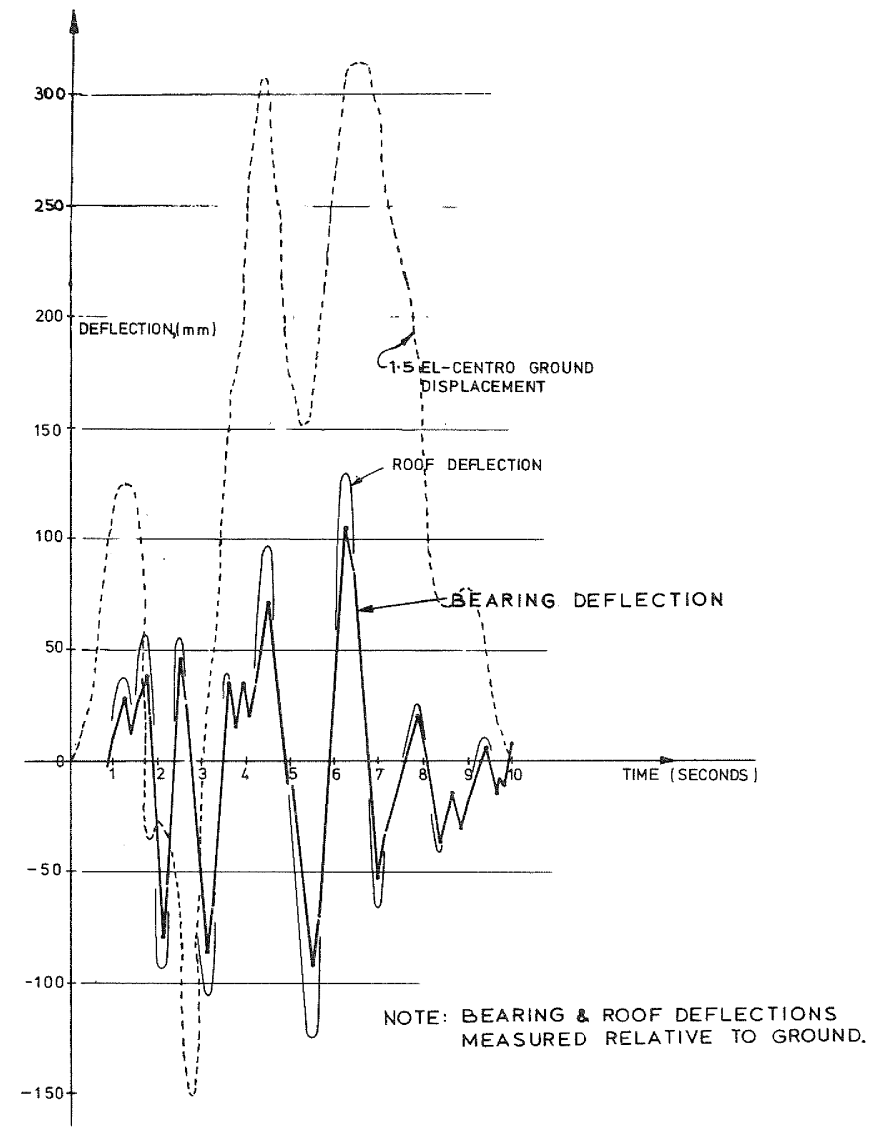




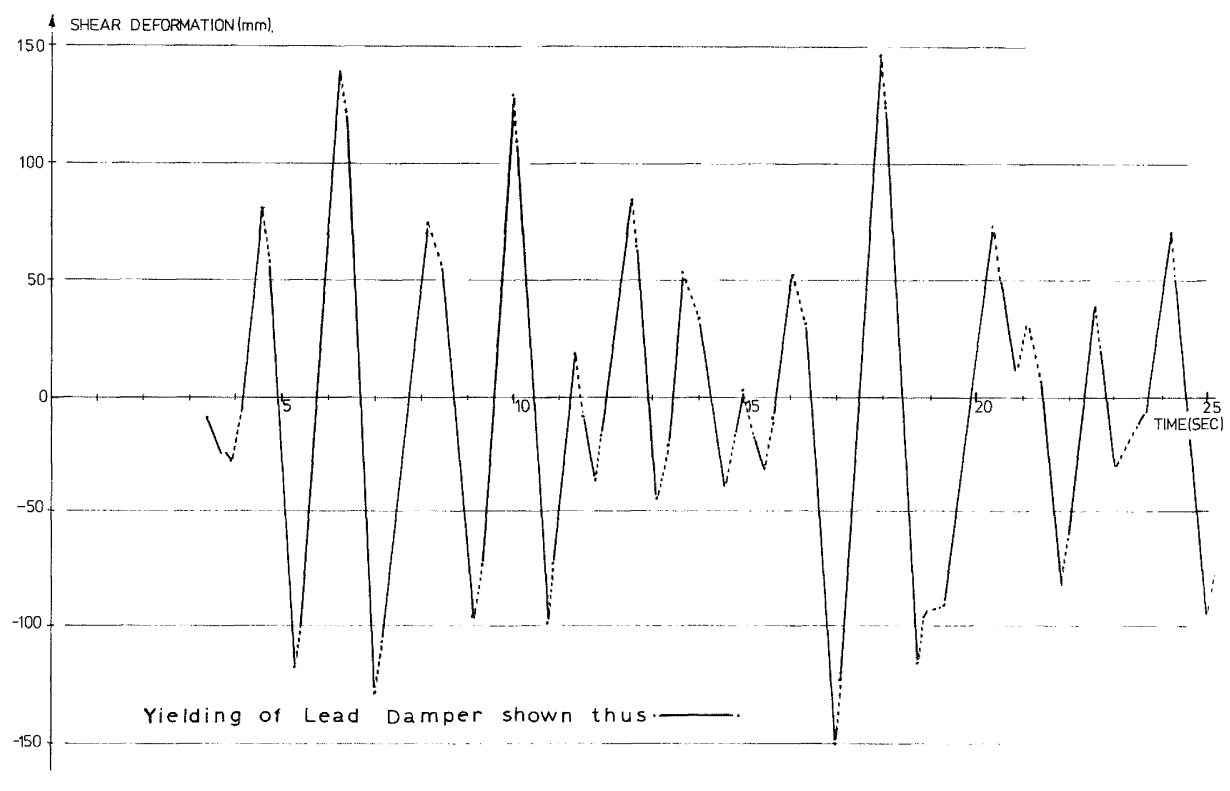

FIGURE 9: SHEAR DEFORMATION TIME-HISTORY OF LEAD DAMPER/BEARING. A1 EARTHQUAKE, 3\% CRITICAL DAMPING

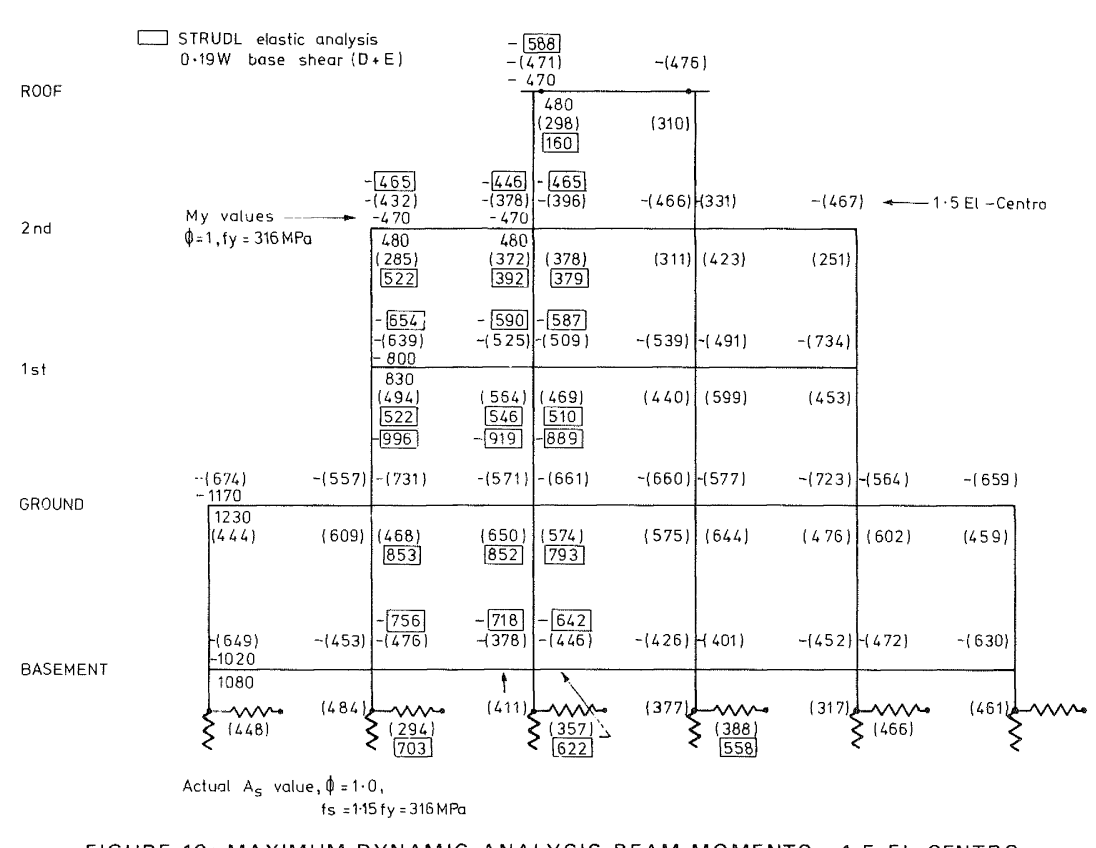

FIGURE 10: MAXIMUM DYNAMIC ANALYSIS BEAM MOMENTS - 1.5 EL-CENTRO

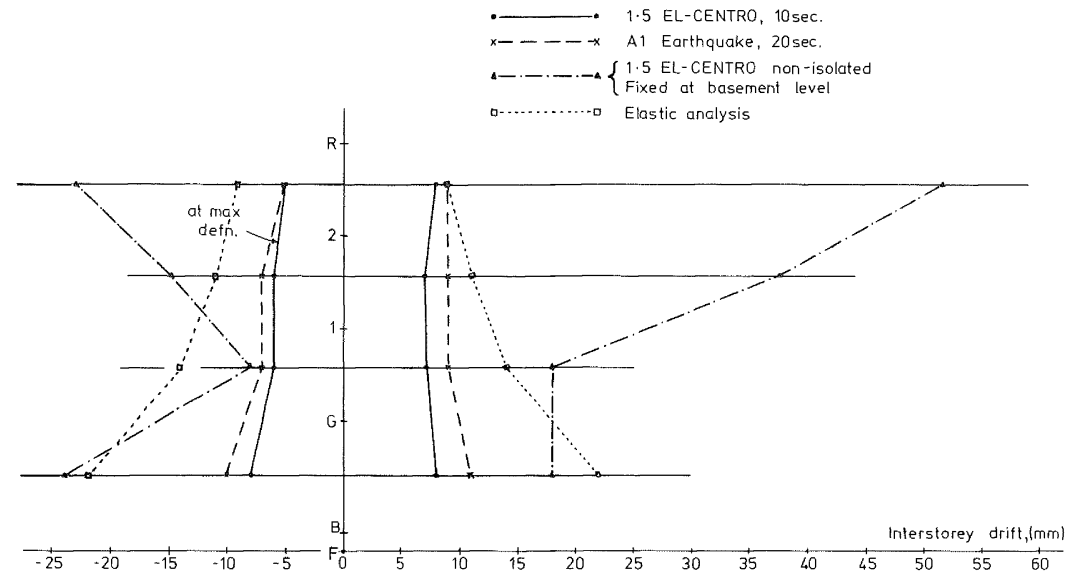

FIGURE 11: INTERSTORY DRIFTS UNDER VARIOUS EARTHQUAKES

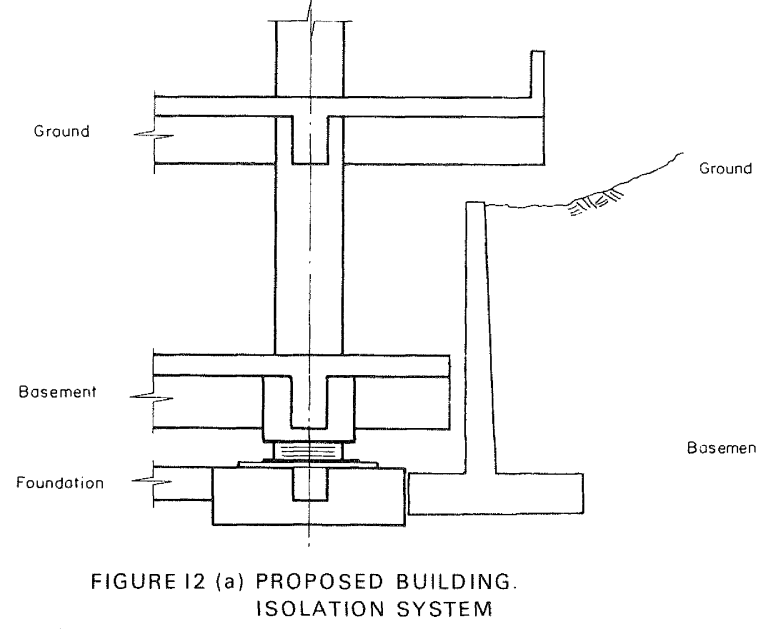

(b) SUGGESTED ISOLATION SYSTEM FOR FUTURE BUILDINGS 